\title{
Suicide and Suicidal Behavior
}

\author{
Yari Gvion, $\mathrm{PhD},{ }^{1}$ \\ Alan Apter, $\mathrm{MD}^{2}$
}

\begin{abstract}
Suicidal behavior is a major public health problem. As it has for decades, suicide remains one of the leading causes of death in the western world. This paper reviews the literature and the latest developments on the research and knowledge of suicide behavior and death from suicide.

The keywords: suicide, psychopathology, mental pain, impulsivity, aggression and communication difficulties were entered into databases: PubMed, PsychLit and ProQuest. Significant articles were scrutinized for relevant information.

According to WHO estimates for the year 2020, approximately 1.53 million people will die from suicide, and ten to 20 times more people will attempt suicide worldwide. These estimates represent on average one death every 20 seconds and one attempt every one to two seconds. Although of low predictive value, the presence of psychopathology is probably the single most important predictor of suicide. Accordingly, approximately 90 percent of suicide cases meet criteria for a psychiatric disorder, particularly major depression, substance use disorders, cluster B personality disorders and schizophrenia. Other more transient factors that reflect an imminent risk of suicide crisis and therefore require immediate intervention include unbearable mental pain and related experiences of depression and hopelessness. Problems with help-seeking, social communication and self-disclosure also pose a suicide risk, as do personality traits of aggression and impulsivity. All these factors are highly correlated with suicidal behavior across psychiatric samples and nosological borders.

Although suicidal behavior has been well studied, empirically and clinically, the definition of the different subtypes and phenotypes of suicidal behaviors and mechanisms underlying some of the risk factors (such as aggression, impulsivity, suicide intent) remain unclear. Reducing the increasing trend of suicide rates among the most vulnerable populations will require further research. Hopefully this review will contribute to the understanding of this phenomenon and to the development of preventive initiatives
\end{abstract}

\footnotetext{
${ }^{1}$ Department of Psychology, Bar Ilan University, Ramat Gan, Israel.

${ }^{2}$ Feinberg Child Study Center, Schneider's Children's Medical Center of Israel. Petach Tikvah and Sackler Faculty of Medicine, Tel Aviv University, Tel Aviv, Israel.
}

Corresponding author Contact Information: Yari Gvion PhD at yari@kadi.co.il; Department of Psychology, Bar Ilan University, Ramat Gan 52900, Israel. 
Keywords: suicide, suicidal behavior, impulsivity, aggression, mental pain, communication difficulties

Recommended Citation: Gvion Y, Apter A. Suicide and suicidal behavior. Public Health Reviews. 2012;34: epub ahead of print.

\section{INTRODUCTION}

Suicidal behavior is a major public health priority. As it has for decades, suicide remains one of the leading causes of death in the western world. The costs of suicide are not only loss of life, but the mental, physical and emotional stress imposed on family members and friends. Other costs are to the public resources, as people who attempt suicide often require help from health care and psychiatric institutes.

Suicide is a final act of behavior that is probably the end result of interactions of several different factors. It is a complex entity, involving biological, genetic and environmental risk factors. Sociopolitical factors are also pertinent to the understanding of suicide. Thus Durkheim ${ }^{1}$ in his historical treatise on suicide coined the terms anomy, egoistic and altruistic. These ideas are still inferential today. Predictors of suicidal behavior and risk factors include a history of previous suicide attempts, certain demographic variables, clinical symptoms and issues related to medical and social support. ${ }^{2-4}$

The aim of this paper is to review the literature and the latest developments on the research and knowledge of suicidal behavior and death from suicide. In order to systematically review the literature on the subject, the literature databases Pubmed, PsychLit and ProQuest were searched using the keywords: suicide, psychopathology, mental pain, impulsivity, aggression and communication difficulties References were identified and grouped so as to delineate the major contributions surrounding the issue.

\section{DEFINITIONS: SUICIDE AND SUICIDAL BEHAVIOR}

Suicide is defined as an act of intentionally terminating one's own life. ${ }^{5,6}$ However, this definition does not do justice to the complexity of the concept and the numerous usages of terms across studies. Thus the nomenclature for suicidal ideation and behavior has been the subject of considerable international attention and debate..$^{711}$ The nomenclature of suicide behaviors without fatal outcome varies as well. Sometimes they are referred to as "suicidality" while others term these as "suicide-related behaviors" or "suicidal behavior". ${ }^{11,12}$ A suicide attempt should possess the following 
characteristics: (a) self-initiated, potentially injurious behavior; (b) presence of intent to die; and (c) nonfatal outcome. ${ }^{13}$

Other related behaviors and definitions relevant to this review include deliberate self-harm (DSH), non-suicidal self injury (NSSI), suicidal threats and suicidal gestures. ${ }^{13}$ There is also some value in separating out nearlethal or medically serious suicide attempt (MSSA) from the non-medically serious suicide attempt (NMSSA). ${ }^{14}$

\section{EPIDEMIOLOGY}

The World Health Organization (WHO) estimates that almost one million people die by suicide each year worldwide, representing an annual global suicide mortality rate of 16 per $100,000 .{ }^{15}$ In the United States alone suicide claims over 32,500 lives annually. ${ }^{16,17}$ Besides the increasing number of deaths by suicide, suicide attempts are even more prevalent. It is estimated that they are twenty-fold more frequent in the general population. ${ }^{18,19}$ Suicide attempts are associated with significant morbidities and constitute a major predictor of later suicide. ${ }^{15,20}$

However, incidence of suicide is under-reported in the world due to a number of reasons: In some instances, and for different reasons, (for example religious and/or social reasons) suicide as the cause for death might be hidden; in some areas it is completely unreported. ${ }^{21}$ In many countries around the world, particularly those that are less developed, ${ }^{22}$ basic data on the prevalence and risk factors for suicide and its immediate precursors-suicidal ideation, plans and attempts-are unavailable. Therefore real figures may be higher than reported ${ }^{23}$ (see also $^{24-26}$ ). Nevertheless, from reported cases, certain trends are apparent. According to WHO estimates for the year 2020 and based on current trends, approximately 1.53 million people will die from suicide, and ten to 20 times more people will attempt suicide worldwide. Those estimates represent on average one death every 20 seconds and one attempt every one to two seconds. ${ }^{23}$

When the WHO suicide data are separated according to geographic regions, the highest rates in each region, except for Europe, are found in island countries such as Cuba, Japan, Mauritius and Sri Lanka. The lowest rates as a whole are found in the Eastern Mediterranean Region, which comprises mostly Islamic countries and some Central Asian republics that were part of the former Soviet Union. ${ }^{23}$ Recent studies in several low- and middle-income countries such as China and India suggest the occurrence of suicidal behaviors may differ markedly from high-income countries. For instance, one work suggests that gender and the presence of mental 
disorders play less of a role in the occurrence of suicidal behaviors in lowand middle-income countries. ${ }^{24}$

In a worldwide project published in 2008 by the WHO World Mental Health (WMH) Survey Initiative, surveys were carried out in 17 countries. A total of 84,850 adults were interviewed regarding suicidal behaviors, socio- demographic and psychiatric risk factors. ${ }^{27}$ The regions of Africa, the Americas, Asia and the Pacific, Europe and the Middle East were included. Of the countries surveyed, China, Colombia, Lebanon, Mexico, Nigeria, South Africa and Ukraine were classified as less developed or lowand middle-income countries, All other survey countries were classified as high-income countries. ${ }^{28}$ Although the authors found substantial crossnational variation in their results, they also found evidence of important consistencies, including the fact that 60 percent of transitions from ideation to first attempt occurred within the first year after ideation onset. In addition, the following risk factors were identified as strong diagnostic risk across countries: female gender, younger age, fewer years of education, unmarried status and the presence of a mental disorder. The strongest diagnostic risk factors were mood disorders in high-income countries but impulse control disorders in low- and middle-income countries. ${ }^{28}$

In another thorough and systematic review on the epidemiology of suicide, Nock, et al. (2008) ${ }^{23}$ reviewed US governmental data on suicide and suicidal behavior and conducted a review of studies on the epidemiology of suicide published from 1997 to 2007. They examined the prevalence of trends, in risk and protective factors for suicidal behavior in the US and cross-nationally. The data revealed that completed suicide is more prevalent among men, whereas nonfatal suicidal behaviors are more prevalent among women and persons who are young, are unmarried, or have a psychiatric disorder. Adults had a lower lifetime prevalence of suicidal behavior than adolescents, overall and for each type of suicidal behavior examined. The authors suggested that this difference may be attributable to underreporting of lifetime suicide behavior by adults.

\section{RISK FACTORS}

\section{Psychopathology}

The correlation between suicidality and psychopathology is well documented in the literature. ${ }^{29}$ Most people, including youth, who contemplate, attempt and/or die from suicide suffer from one or more psychopathologies. ${ }^{30,31}$ Mood disorders are the most common mental disorders reported as associated 
with suicidal behavior. ${ }^{32-34}$ Several studies found a correlation between suicide attempters suffering from depression and high levels of impulsive and aggressive behaviors. ${ }^{30}$

Others who tend to engage in suicidal behaviors are those suffering from schizophrenia. Methods used in suicide attempts by individuals suffering from schizophrenia are largely nonviolent. ${ }^{35}$ These results were supported in work by Symond and colleagues $(2006)^{36}$ that compared suicidal intent, violence of method and motive in patients suffering from schizophrenia and adjustment reactions with self-harm. They also examined the effect of positive symptoms of schizophrenia on self-harm. The schizophrenic group did not significantly use more violent methods. The use of a violent method was also not significantly associated with the presence of positive symptoms in schizophrenia.

Another mental disorder strongly associated with suicidal behavior and completion is Borderline Personality Disorder (BPD). Several studies found that three out of four individuals suffering from BPD will engage in suicidal behavior. ${ }^{37}$ On average, individuals with BPD make three lifetime attempts ${ }^{38}$ and ten percent of BPD patients will complete suicide. ${ }^{39}$ Psychological autopsies have reported a wide range of mortality due to borderline personality disorder (between $7 \%$ and 38\%) which probably reflects different methodologies of diagnostic ascertainment. ${ }^{40}$

Suicide attempts in alcoholics are common and have been also linked to behavioral inhibition, impulsivity and aggression with the use of violent methods for the attempts. ${ }^{41-43}$ One study found that 43 percent of the subjects with alcohol dependency reported life-time suicide attempts. ${ }^{44}$ Similar results were obtained in a study that compared two groups of psychiatric subjects, a group with substance dependence and another without. The substance dependent group had a tendency towards more impulsive aggressive personality and a history of suicidal thoughts and behaviors ${ }^{45}$ However, the statistical significance of these finding was low $(\mathrm{p}>0.05)$.

Although of low specificity, the presence of psychopathology is probably the single most important predictor of suicide. Accordingly, approximately 90 percent of suicide cases meet criteria for a psychiatric disorder, previously documented, particularly major depression, substance use disorders, cluster B personality disorders and schizophrenia. ${ }^{46,47}$ However, despite the fact that most suicide attempters do suffer from psychopathology, most persons with psychiatric disorders do not attempt suicide. Therefore other factors over and above psychopathology must be involved. 


\section{TRAITS: AGGRESSION AND IMPULSIVITY}

\section{Aggression}

Multiple epidemiologic, clinical, retrospective, prospective, and family studies have identified a strong link between aggression and suicide. ${ }^{48,49}$ Research suggests a common neurobiology of suicide and other forms of aggressive behavior. ${ }^{50}$ Lower levels of central serotonin are associated with suicide attempts and specifically more lethal suicide attempts after controlling for psychiatric illness. ${ }^{51,52}$ While the research relating aggression to the presence of suicidal behavior shows consistent findings, the relation between aggression and the severity of the suicidal attempt is variable.

In an attempt to study the relationship between aggression and suicide completion, different approaches have been taken. One of them compared medically serious suicide attempters (MSSAs) to healthy controls. Trait aggression was significantly higher in the MSA group ${ }^{53}$ however, that study did not include a non-medically serious suicide attempters (NMSSAs) control group. In another study designated to look for differences among those with specific psychiatric pathologies, personality-disordered individuals, particularly those who are more impulsive and aggressive and who have a co-morbid depressive disorder were found to have a higher risk for more frequent and more medically-severe suicidal behavior in comparison to individuals with Major Depressive Disorder (MDD) or Bipolar Depression (BD) alone. ${ }^{54,55} \mathrm{In}$ a different perspective on the relation between suicide and aggression, several studies focused on choices of methods for the suicide attempt. They found that the use of violent methods of suicide is a behavioral marker of a higher level of lifetime impulsive-aggressive behaviors ${ }^{56}$ and is more often used by males than females, and in suicide completers affected by psychosis. Others even suggest that aggression may be indirectly linked to high lethality attempts. It was found that violence during the last year of life is more frequent among suicide victims than accident victims. ${ }^{57}$ On the other hand, Soloff and colleagues (2005) ${ }^{58}$ found that high lethality and low lethality suicide attempters with borderline personality disorder (BPD) were not different in their levels of aggression.

Gender is a factor that is closely related to suicide attempts and to the lethality of the attempt. It has been found across different studies, that actual suicide is more prevalent among men, whereas nonfatal suicidal behaviors are more prevalent among women. ${ }^{25,59,60}$ Aggression or one of its facets (e.g., anger, violence.) might be related to the difference found between female and masculine suicidal behavior and completion. 
Violence, Suicide and Gender: Among individuals with histories of violence, gender does not appear to protect against suicide risk. Yet, relatively less research has focused on potential gender differences in the relationships between suicidality, violence, and associated variables. Studies indicate that gender is an important variable that might influence the relation between violence and suicidality. Becker, et al. (2007) ${ }^{61}$ studied the effect of gender on the prediction of suicidality and violent behavior among both male and female subjects. Gender made an independent contribution to the prediction of both suicide risk and violence risk, but in opposite ways, with female gender contributing to the suicide risk and male gender contributing to violence. Similarly, studies on exposure to violence demonstrated gender-specific associations between exposure to violence and suicide risk. ${ }^{62-64}$ Exposure to community violence may be an additional risk factor for both conditions, especially in boys. ${ }^{64,65}$

In considering depression, male symptoms differ from those of females. Thus male suicidality can be studied through the quite intricate context of depression, suicide, auto-aggressive self neglect and hetero-aggressive violence. ${ }^{66}$ Male depression is often acted out and camouflaged by alcohol abuse, drug addiction, poor impulse control and aggressive and violent acting out. ${ }^{67}$

\section{Impulsivity}

Impulsivity, a prominent construct in most theories of personality, encompasses a broad range of behaviors that reflect impaired self-regulation, such as poor planning, premature responding before considering consequences, sensation-seeking, risk-taking, an inability to inhibit responses, and preference for immediate over delayed rewards. ${ }^{68,69}$ Suicide attempts are often impulsive and many studies have identified impulsivity as a common correlate and risk factor for suicidal behavior. ${ }^{70-72}$ The relationship between impulsivity and suicidal behavior was found across different nosological entities, ${ }^{73-76}$ and is also true of non-psychiatric populations. ${ }^{77}$ There is a marked lack of consensus on the relationship between impulsivity and the medical seriousness of the attempt. Although some authors believe impulsivity is a characteristic of nonlethal suicide attempts or suicide gestures ${ }^{78}$ others report evidence of higher levels of impulsivity in those who die by suicide than in those who do not. ${ }^{79-81}$ The dissimilarities may be explained by the confusion between the state and trait dimensions of the impulsivity-suicide relationship, differing definitions of impulsivity, the measures used and the population studied. 
The Role of Planning, Time Elapsed, and Intent: It is important to distinguish between a suicidal act that can be impulsive (or not) and a person who can be impulsive or not. ${ }^{82}$ Recent research has shown that although people who attempt suicide tend to be more impulsive than those who do not, the actual act of completed suicide is often not made impulsively. ${ }^{76}$ Suicidal planning is related to, but not synonymous with, suicidal intent. Planned suicide involves a more subjective element drawn from the desired outcome and perceived lethality of the act of self-harm. ${ }^{83}$

One way to operationalize impulsivity of the suicide attempt is to look at the degree of objective signs of planning, as measured by the planning subscale of the Suicide Intent Scale (SIS). ${ }^{78,84-86}$ Impulsivity may also be evaluated by the length of the interval between the decision to attempt suicide and the actual attempt. One of the conservative criterions suggested by Williams, and colleges (1980) ${ }^{87}$ is five minutes premeditation. Others suggested longer intervals of 20 minutes,$^{88}$ two hours ${ }^{89}$ and 24 hours $^{90}$. Simon, et al. (2001) ${ }^{91}$ found that 24 percent of survivors of near-lethal suicide attempts had thought about their attempt for less than five minutes. Those who made their attempt within five minutes of deciding to do so were less likely to have considered another method of suicide. They also had a greater likelihood of discovery and a lower expectation of death. These findings were consistent with the description of such attempts as impulsive.

Other authors emphasized the mediatory role of the intent to die and the subject's intention at the time of the suicide attempt. Hawton (1986) ${ }^{92}$ found that less than 50 percent of subjects with a history of suicide attempts really wanted to die, and he defined their attempts as little-planned impulsive acts. Motives reported in impulsive suicides ranged from escaping from an intolerable situation to manipulation. ${ }^{85}$

The association between aggression, impulsivity and suicidal behavior is documented in research and in clinical practice across different diagnoses. ${ }^{93-96}$ There is also some evidence that this association is stronger in younger individuals and decreases in importance with age ${ }^{97}$ However the mechanism by which impulsivity and aggression combine with psychopathology to produce suicidal behavior remains uncertain. Current models suggest that aggression and impulsivity may contribute to a summary factor predictive of suicidal behavior in patients with various types of psychiatric diagnoses.$^{51}$ This is particularly true for a subtype of aggression-reactive aggression-marked by angry, impulsive responses to perceived acute stress ${ }^{98,99}$ which is externally directed and related to other manifestations of impulsivity ${ }^{100,101}$ predisposing individuals to the development of psychopathology strongly associated with suicide (e.g., substance abuse and cluster B personality disorders). ${ }^{97,102}$ Reactive aggression has been associated 
with lowered serotonin-mediated brain activity, interpersonal rejection, and a pattern of emotional disregulation in the context of interpersonal difficulties and other stressful life events, all of which can lead to suicide. ${ }^{103}$ Disinhibition may predispose individuals to suicidal behavior when it occurs in conjunction with high levels of hostility-aggression. ${ }^{104}$

The literature is somewhat confusing probably since, as noted above, impulsivity is an ill-defined concept, and has both a trait and a state aspect to it; different nomenclatures are used for aggression and the operational definitions of impulsivity, aggression and suicidal behavior also vary a lot. Other problems arise from the fact that the boundaries between impulsivity and aggression are unclear and many disparate measures are used. From clinical experience and much research there is intuitively a very important role for impulsivity and aggression in the understanding of suicide and thus further research based on clearer conceptual refinement in this area is imperative.

\section{INTRAPERSONAL AND INTERPERSONAL FACTORS}

\section{Mental Pain}

Mental pain is an important concept that is studied from different perspectives: theoretically, clinically and empirically. The most extensive contribution to the clarification of the concept has been provided by Shneidman who coined the term 'psychache' (i.e., unbearable mental pain) ${ }^{6,105}$ According to his view psychache is the result of frustrated or thwarted essential needs (e.g., to love; to have control; to protect one's self image; to avoid shame, guilt, humiliation; to feel secure) that arouse a mixture of negative emotions like guilt, shame, hopelessness, disgrace, rage and defeat. Those negative feelings turn into a generalized experience of unbearable mental pain - a state of emotional perturbation. ${ }^{105}$ The pain might be so intensive that one might wish to escape the unbearable pain by committing suicide.

Orbach, Mikulincer, et al. (2003) $)^{106}$ have conceptualized mental pain as a wide range of subjective experiences characterized as an awareness of negative changes in the self and in its functions accompanied by negative feelings. They have created the Orbach and Mikulincer Mental Pain (OMMP) Scale assessing the dimensions and the intensity of this experience. Their study and others confirm that mental pain and related experiences such as hopelessness and depression are inextricably related to suicide. ${ }^{106}$ However these studies suggest that, although mental pain is 
related to anxiety, hopelessness and depression, it does not overlap with these concepts. Moreover, mental pain seems to allow a window into the suffering of suicidal patients over and above those related experiences.

\section{Loneliness, Alienation, Communication Difficulties}

Several studies have highlighted the significant role of interpersonal risk factors in suicide. ${ }^{107,108}$ People who are able to share their difficulties with family, friends or others benefit in various ways. Communication enhances intimate relations and helps to cope with stress and traumatic events. ${ }^{109,110}$ People who communicate their difficulties to their environment are less likely to kill themselves. On the other hand, when communication fails, the risk for suicide arises. For instance the association between social isolation and suicidal ideation, attempts, and lethal suicidal behavior was found in various samples varying in age, nationality, and clinical severity. ${ }^{111}$ Several empirical studies have demonstrated associations between lethal suicidal behavior and various facets of communication difficulties, including loneliness, social withdrawal and isolation, lack of self disclosure, living alone and having few social supports. ${ }^{108,112}$ Thus it appears that difficulties in communication are a meaningful factor influencing suicidal behavior in general and lethal suicide attempts in particular.

The well-known interpersonal theory of suicide of Joiner offers some insight to the way mental pain and communication difficulties are factors that work together to motivate a person to engage in suicidal behavior. Joiner (2005) $)^{113}$ proposed the interpersonal psychological theory of attempted and completed suicide (also known as the "crescendo" model of suicide behavior), which claims that to die by suicide an individual must have both the desire and the capability. This occurs rarely, as few people have the desire, and even fewer the capabilities, to take their own life. The theory further posits that the desire to die by suicide stems from a thwarted sense of belongingness and the feeling of being a burden on others. Mental pain is a concept that entails the feeling of thwarted belongingness and that one's existence burdens the family and friends. This feeling is central to the etiology of suicide. However, the capability to engage in suicidal behavior is separate from the desire to engage in suicidal behavior. The capability to die by suicide is acquired through a process of habituation that allows the individual to overcome the pain and fear associated with suicidal behavior. Pre-existing factors sometimes accelerate the process.

According to Joiner (2005), ${ }^{113}$ impulsivity is only distally related to suicide: impulsive individuals may be more likely to have experiences that are painful or provocative which, in turn, confer an increased risk of suicidal 
behavior via habituation. Along the same lines, Witte et al. (2008) ${ }^{114}$ proposed that certain behaviors may promote the individual's capability of committing lethal suicide, such as prostitution, drug use, self-mutilation, and violence. With practice and repetition, the fear- and pain-inducing aspects of such provocative behaviors are reduced, and they become rewarding. Those behaviors may be related to other factors mentioned in this review (aggression and impulsivity) and their relation to suicidal behavior.

These assumptions may open further research questions about the relationship between impulsivity, aggression, mental pain and communication difficulties and suicidal behavior. If impulsive individuals commit suicide after planning and gradual adaptation to fear and pain, the implications are important on both the theoretical and clinical fronts.

\section{TREATMENT}

A full review of the recent developments in the treatment of suicide behavior is beyond the scope of this article. However in addition to traditional therapies such as psychoanalytic oriented psychotherapy, there have been interesting contributions from traditional cognitive behavior such as problem solving, ${ }^{115}$ Cognitive-Behavioral Therapy for Suicide Prevention (CBT-SP) ${ }^{116}$ and dialectic therapy ${ }^{40}$. Finally mention should be made of a recent project, the Treatment of Adolescent Suicide Attempters study (TASA) which attempts to integrate different modalities in a flexible manner which can be suited for the individual adolescent. ${ }^{117}$

\section{SUMMARY}

Suicide is a complex and multidimensional phenomenon stemming from the interaction of several factors. Suicide remains an important and major cause of death in various populations' samples varying in age, nationality, and clinical severity. It cuts through nosological boundaries and across psychiatric diagnoses; it also characterizes non-psychiatric populations.

Non fatal suicidal behavior is also associated with a great deal of suffering and risk. Although suicidal behavior has been extensively studied, major problems still remain to be solved. Among them are those of definition of different subtypes and phenotypes of suicidal behaviors, and associated factors (such as aggression, impulsivity, suicide intent). The future probably lies in looking at some basic underlying biological phenotypes such those described in the work of Mann and Currier, $(2009)^{50}$ or some of the sociological problem behavior theories of Jessor (2005). ${ }^{118}$ 
Since aggression impulsivity, mental pain and communication difficulties are so ubiquitous in suicidal behaviors and so obvious a target for intervention, these areas of inquiry must be pursued despite all the inherent difficulties involved in such endeavor.

Our group recently suggested a model that may be pertinent to this discussion. ${ }^{14}$ A stressful life event can produce mental pain, depression, and hopelessness. Persons with good communication skills may gain support from friends and family; others may use suicidal behavior as a means of communication. When social communication is blocked, however, the person may feel "trapped". ${ }^{119}$ The pernicious combination of unbearable mental pain and inability to signal one's distress to others can lead to a serious attempt to kill oneself. We are currently planning a study based on this model to gain more insight into the contribution of impulsivity and aggression in people in states of emotional entrapment. We hypothesize that impulsivity and aggression under this condition will serve to provoke a medically serious suicide act.

Suicidal behavior remains an important clinical problem and a major cause of death in youth and adults. Further recognition of the contextual factors and personality traits can help researches in developing the next generation of interventions for suicidal people and will help clinicians in implementing sensitive care in the treatment of suicidal behavior.

The relationship between impulsivity, aggression, mental pain communication difficulties and suicidal behavior continues to intrigue researchers. We hope that this review might provide an impetus for further studies in this field.

\section{Acronyms list:}

$\mathrm{BPD}=$ Borderline personality disorder

MSSA = Medically serious suicide attempt

$\mathrm{WMH}=$ World Mental Health Survey Initiative

Conflicts of Interest: None declared.

About the Authors: Yari Gvion, $\mathrm{PhD}$, is a supervising clinical psychologist who has worked for many years in a psychiatric hospital and in private clinic. She teaches in the Clinical Division of the Psychology Departments at Bar-ILan University and Tel Aviv-Yafo College. Her thesis examined the multi-dimensional effects of risk factors for suicide attempts, and the factors that can distinguish between different levels of severity of the suicidal attempt.

Alan Apter, MD, is a professor of psychiatry at the Sackler School of Medicine at the University of Tel Aviv, where he served as a chair of the department. He is also the director of the Feinberg Child Study Center at Schneider's Children's Medical Center of Israel, fellow of numerous professional societies and organizations and has published more than 300 articles and chapters as well as two books. 


\section{REFERENCES:}

1. Durkheim E. Suicide: A Study in Sociology. Spoulding JA, (translator). Simpson G, (editor). New York, NY: Free Press; 1897/1951.

2. Barraclough BM, Pallis DJ. Depression followed by suicide: a comparison of depressed suicides with living depressives. Psychol Med. 1975;5:55-61.

3. Beck AT, Steer RA, Kovacs M, Garrison B. Hopelessness and eventual suicide: a 10 year prospective study of patients hospitalized with suicidal ideation. Am J Psychiatry. 1985;142:559-63.

4. Fawcett J, Scheftner W, Clark D, Hedeker D, Gibbons R, Coryell W. Clinical predictors of suicide in patients with major affective disorders: a controlled prospective study. Am J Psychiatry. 1987;144:35-40.

5. Nock MK, Borges G, Bromet EJ, Alonso J, Angermeyer M, Beautrais A, et al. Cross-national prevalence and risk factors for suicidal ideation, plans and attempts. Br J Psychiatry. 2008;192:98-105.

6. Shneidman ES. The Definition of Suicide. New York, NY and London: John Wiley and sons; 1985.

7. De Leo D, Burgis S, Bertolote JM, Kerkhof AJ, Bille-Brahe U. Definitions of suicidal behavior: lessons learned from the WHO/EURO multicentre study. Crisis. 2006;27:4-15.

8. O'Carroll PW, Berman AL, Maris RW, Moscicki EK, Tanney BL, Silverman MM. Beyond the tower of Babel: a nomenclature for suicidology. Suicide Life Threat Behav. 1996;26:237-52.

9. Silverman MM, Berman AL, Sanddal ND, O'Carroll PW, Joiner TE. Rebuilding the Tower of Babel: a revised nomenclature for the study of suicide and suicidal behaviors. Part 1: Background, rationale, and methodology. Suicide Life Threat Behav. 2007; 37:248-63.

10. Silverman MM, Berman AL, Sanddal ND, O'Carroll PW, Joiner TE. Rebuilding the Tower of Babel: a revised nomenclature for the study of suicide and suicidal behaviors: Part 2: Suicide-related ideations, communications and behaviors. Suicide Life Threat Behav. 2007;37:264-77.

11. Heilbron N, Compton JS, Daniel SS, Goldston DB. The problematic label of suicide gesture: alternatives for clinical research and practice. Prof Psychol Res Pr. 2010;41:221-7.

12. Van Orden KA, Witte TK, Cukrowicz KC, Braithwaite SR, Selby EA, Joiner TE Jr. The Interpersonal theory of suicide. Psychol Rev. 2010;117:575-600.

13. Apter A. Clinical aspects of suicidal behavior relevant to genetics. Eur Psychiatry. 2010;25:257-9.

14. Levi Y, Horesh N, Fischel T, Treves I, Or E, Apter A. Mental pain and its communication in medically serious suicide attempts: an "impossible situation" J Affect Disord. 2008;111:244-50.

15. World Health Organization. Suicide Prevention (SUPRE). WHO: 2007. Available from URL: http://www.who.int/mental_health/prevention/suicide/ suicideprevent/en/ (accessed 23 August 2012). 
16. Center for Disease Control. Deaths, percent of total deaths, and death rates for the 15 leading causes of death: United States and each State, 2003. CDC: 2006. Available from URL: http://www.cdc.gov/nchs/data/dvs/lcwk9_2003. pdf (accessed 23 August 2012).

17. Kung HC, Hoyert DL, Xu JQ, Murphy SL. Deaths: Final data for 2005. In: National Vital Statistics Reports, Volume 56. Hyattsville, MD: National Center for Health Statistics; 2008.

18. Cutcliffe JR. Research endeavours into suicide: a need to shift the emphasis. $\mathrm{Br}$ J Nurs. 2003;12:92-9.

19. Black DW, Bell S, Hulbert J, Nasrallah A. The importance of Axis II in patients with major depression. J Affect Disord. 1988;14:115-22.

20. Diaconu G, Turecki, G. Family history of suicidal behavior predicts impulsiveaggressive behavior levels in psychiatric outpatients. J Affect Disord. 2009;113:172-8.

21. Bertolote JM, Fleishman, A. A global perspective in the epidemiology of suicide. Suicidologi. 2002;7:6-8.

22. Vijayakumar L, Nagaraj K, Pirkis J, Whiteford H. Suicide in developing countries 1: frequency, distribution, and association with socioeconomic indicators. Crisis. 2005;26:104-11.

23. Nock MK, Borges G, Bromet EJ, Cha CB, Kessler RC, Lee S. Suicide and suicidal behavior. Epidemiol Rev. 2008;30:133-54.

24. Moscicki EK. Epidemiology of suicide. In: The Harvard Medical School Guide to Suicide Assessment and Intervention. Jacobs DG, (editor). Jossey-Bass; 1999, pp. 40-51.

25. Kessler RC, Berglund P, Borges G, Nock MK, Wang PS. Trends in suicide ideation, plans, gestures, and attempts in the United States, 1990-1992 to 2001-2003. JAMA. 2005;293:2487-95.

26. Weissman MM, Bland RC, Canino GJ, Greenwald S, Hwu HG, Joyce PR, et al. Prevalence of suicide ideation and suicide attempts in nine countries. Psychol Med. 1999;29:9-17.

27. World Health Association. The WHO World Mental Health Surveys: Global Perspectives on the Epidemiology of Mental Disorders. Kessler RC, Ustun TB, (editors). Cambridge University Press; 2008.

28. World Bank. World Development Indicators 2003. The World Bank, 2003.

29. Gvion Y, Apter A. Aggression, impulsivity and suicide behavior: a review of the literature. Suicide Life Threat Behav. 2011;15:93-112.

30. Groholt B. \& Ekeberg O. Prognosis after adolescent suicide attempt: mental health, psychiatric treatment, and suicide attempts in a nine-year follow-up study. Institute for Psychiatry at the University of Oslo. Suicide Life Threat Behav. 2009;39:125-36.

31. Renaud J, Berlim MT, McGirr A, Tousignant M, Turecki G. Current psychiatric morbidity, aggression/impulsivity, and personality dimensions in child and adolescent suicide: a case-control study. J Affect Disord. 2008;105:221-8. 
32. Beautrais A. Suicide and serious suicide attempts in youth. A multiple-group comparison study. Am J Psychiatry. 2003;160:1093-9.

33. Becker DF, Grilo CM. Prediction of suicidality and violence in hospitalized adolescents: comparisons by sex. Can J Psychiatry. 2007;52:572-81.

34. Zhang J, Xiao S, Zhou L. Mental disorders and suicide among young rural Chinese: a case-control psychological autopsy study. Am J Psychiatry. 2010;167:773-81.

35. Kerkhof AJFM. Attempted suicide: Patterns and trends. In: The international handbook of suicide and attempted suicide. Hawton K, van Heeringen K. (editors). Chichester Wiley; 2000.

36. Symond CS, Taylor S, Tippins V, Tirkington D. Violent self-harm in schizophrenia. Suicide Life Threat Behav. 2006;36:44-9.

37. Soloff PH, Lis JA, Kelly T, Cornelius J, Ulrich R. Risk factors for suicidal behavior in borderline personality disorder. Am J Psychiatry. 1994;151:131623.

38. Brodsky BS, Groves SA, Oquendo MA, Mann JJ, Stanley B. Interpersonal precipitants and suicide attempts in borderline personality disorder. Suicide Life Threat Behav. 2006;36:313-22.

39. American Psychiatric Association. Diagnostic and statistical manual of mental disorders, fourth edition, text revision: DSM-IV-TR. Washington, DC: APA; 2000.

40. Linehan MM, Cochran BN, Kehrer CA. Dialectical behavior therapy for borderline personality disorder. In: Clinical handbook of psychological disorders: A step-by-step treatment manual (3rd ed.). Barlow DH, (editor). New York, NY: Guilford; 2001, pp. 470-522.

41. Bergman B, Brismar B. Hormone levels and personality traits in abusive and suicidal male alcoholics. Alcohol Clin Exp Res. 1994;18:311-6.

42. Mezzich AC, Giancola PR, Tarter RE, Lu S, Parks SM, Barrett CM. Violence, suicidality, and alcohol/drug use involvement in adolescent females with psychoactive substance use disorder and controls. Alcohol Clin Exp Res. 1997;21:1300-7.

43. Suominen K, Isometsä E, Henriksson M, Ostamo A, Lönnqvist J. Hopelessness, impulsiveness and intent among suicide attempters with major depression, alcohol dependence or both. Acta Psychiatr Scand. 1997;96:142-9.

44. Wojnar M, Ilgen MA, Czyz E, Strobbe S, Klimkiewicz A, Jakubczyk A, et al. Impulsive and non-impulsive suicide attempts in patients treated for alcohol dependence. J Affect Disord. 2009;115:131-9.

45. Pompili M, Innamorati M, Lester D, Akiskal HS, Rihmer Z, del Casale A, et al. Substance abuse, temperament and suicide risk: evidence from a case-control study. J Addict Dis. 2009;28:13-20.

46. Arsenault-Lapierre G, Kim, C, Turecki G. Psychiatric diagnoses in 3275 suicides: a meta-analysis. BMC Psychiatry. 2004;4:37.

47. Cavanagh JT, Carson AJ, Sharpe M, Lawrie SM. Psychological autopsy studies of suicide: a systematic review. Psychol Med. 2003;33:395-405. 
48. Conner KR, Swogger MT, Houston RJ. A test of reactive aggression- suicidal behavior hypotheses: Is there a case for proactive aggression? J Abnorm Psychol. 2009; 118:235-40.

49. Romanov K, Hatakka M, Keskinen E, Laaksonen H, Kaprio J, Rose RJ, Koskenvuo M. Self-reported hostility and suicidal acts, accidents, and accidental deaths: a prospective study of 21,443 adults aged 25-59. Psychosom Med. 1994;56:328-36.

50. Mann JJ, Currier D. Biological predictors of suicidal behavior in mood disorders. In: Oxford Textbook of Suicide Prevention. A Global Perspective. Wasserman D, Wasserman C, (editors). Oxford University Press; 2009, pp. 335-41.

51. Mann JJ, Malone KM. Cerebrospinal fluid amines and higher lethality suicide attempts in depressed inpatients. Biol Psychiatry. 1997;41:162-71.

52. Ninan PT, van Kammen DP, Scheinin M, Linnoila M, Bunney WE Jr, Goodwin FK. CSF 5-hydroxyindoleacetic acid levels in suicidal schizophrenic patients. Am J Psychiatry. 1984;141:566-9.

53. Doihara C, Kawanishi C, Yamada T, Sato R, Hasegawa H, Furuno T, et al. Trait aggression in suicide attempters: a pilot study. Psychiatry Clin Neurosci. 2008;62:352-4.

54. Black DW, Bell S, Hulbert J, Nasrallah A. The importance of Axis II in patients with major depression. J Affect Disord. 1988;14:115-22.

55. McGlashan TH. Borderline personality disorder and unipolar affective disorder. J Nerv Ment Dis. 1987;175:467-73.

56. Dumais A, Lesage AD, Lalovic A, Séguin M, Tousignant M, Chawky N, Turecki G. Is violent method of suicide a behavioral marker of lifetime aggression? Am J Psychiatry. 2005;162:1375-8.

57. Conner KR, Duberstein PR, Conwell Y, Seidlitz L, Caine ED. Psychological vulnerability to completed suicide: a review of empirical studies. Suicide Life Threat Behav. 2001;31:367-85.

58. Soloff PH, Fabio A, Kelly TM, Malone KM, Mann JJ. High-lethality status in patients with borderline personality disorder. J Pers Disord. 2005;19:386-99.

59. Linehan MM. A social behavioral analysis of suicide and parasuicide: implications for clinical assessment and treatment. In: Depression: Behavioral and Directive Intervention Strategies. Glazer HG, Clarkin JF (editors). New York, NY: Garland Press; 1981, pp.229-94.

60. Linehan MM. Suicidal people. One population or two? In: Psychobiology of Suicidal Behaviour. Mann JJ, Stanely M, (editors). New York, NY: Annals of the New York Academy of Sciences; 1986, pp.16-33.

61. Becker DF, Grilo CM. Prediction of suicidality and violence in hospitalized adolescents: comparisons by sex. Can J Psychiatry. 2007;52:572-80.

62. Vermeiren R, Schwab-Stone M, Ruchkin VV, King RA, Van Heeringen C, Deboutte D. Suicidal behavior and violence in male adolescents: a schoolbased study. J Am Acad Child Adolesc Psychiatry. 2003;42:41-8. 
63. Apter A, Gothelf D, Orbach I, Weizman R, Ratzoni G, Har-Even D, Tyano S. Correlation of suicidal and violent behavior in different diagnostic categories in hospitalized adolescent patients. J Am Acad Child Adolesc Psychiatry. 1995;34:912-8.

64. Plutchik R, van Praag HM. Suicide, impulsivity, and antisocial behavior. In: Handbook of Antisocial Behavior. Stoff DM, Breiling J, Maser JD, (editors). New York, NY: Wiley; 1997, pp.101-8.

65. Lambert SF, Copeland-Linder N, Ialongo, NS. Longitudinal associations' between community violence exposure and suicidality. J Adolesc Health. 2008;43:380-6.

66. Rutz W, Rihmer Z. Suicide in men. suicide prevention for the male person. In: Oxford Textbook of Suicide Prevention. A Global Perspective. Wasserman D, Wasserman C, (editors). Oxford University Press; 2009, pp.249-55.

67. Wasserman D, Varnik A. Eklund G. Male suicides and alcohol consumption in the former USSR. Acta Psychiatr Scand.1994;89:306-13.

68. Evenden J. Impulsivity: a discussion of clinical and experimental findings. J Psychopharmacol. 1999;13:180-192.

69. Whiteside SP, Lynam DR. Understanding the role of impulsivity and externalizing psychopathology in alcohol abuse: application of the UPPS Impulsive Behavior Scale. Exp Clin Psychopharmacol. 2003;11:210-7.

70. Horesh N, Rolnick T, Iancu I, Dannon P, Lepkifker E, Apter A, Kotler M. Anger, impulsivity, and suicide risk. Psychother Psychosom. 1997;66:92-6.

71. Horesh N, Gothelf D, Ofek H, Weizman T, Apter A. Impulsivity as a correlate of suicidal behavior in adolescent psychiatric inpatients. Crisis. 1999;20:8-14.

72. Wu CS, Liao SC, Lin KM, Tseng MM, Wu EC, Liu SK. Multidimensional assessments of impulsivity in subjects with history of suicidal attempts. Compr Psychiatry. 2009;50:315-21.

73. Giegling I, Olgiati P, Hartmann AM, Calati R, Möller HJ, Rujescu D, Serretti A. Personality and attempted suicide. Analysis of anger, aggression and impulsivity. J Psychiatr Res. 2009;43:1262-71.

74. Soloff PH, Lynch KG, Kelly TM, Malone KM, Mann JJ. Characteristics of suicide attempts of patients with major depressive episode and borderline personality disorder: a comparative study. Am J Psychiatry. 2000;157:601-8.

75. Zouk H, Tousignant M, Seguin M, Lesage A, Turecki G. Characterization of impulsivity in suicide completers: a clinical, behavioral and psychosocial dimensions. J Affect Disord. 2006;92:195-204.

76. Anestis MD, Selby EA, Joiner TE. The role of urgency in maladaptive behaviors. Behav Res Ther. 2007;45:3018-29.

77. Dougherty DM, Mathias CW, Marsh DM, Papageorgiou TD, Swann AC, Moeller FG. Laboratory-measured behavioral impulsivity relates to suicide. Suicide Life Threat Behav. 2004;34:374-85..

78. Baca-García E, Diaz-Sastre C, Basurte E, Prieto R, Ceverino A, Saiz-Ruiz J, de Leon J. A prospective study of the paradoxical relationship between impulsivity and lethality of suicide attempts. J Clin Psychiatry. 2001;62:560-4. 
79. Dumais A, Lesage AD, Lalovic A, Séguin M, Tousignant M, Chawky N, Turecki G. Is violent method of suicide a behavioral marker of lifetime aggression? Am J Psychiatry. 2005;162:1375-8.

80. Maser JD, Akiskal HS, Schettler P, Scheftner W, Mueller T, Endicott J, et al. Can temperament identify affectively ill patients who engage in lethal or near lethal suicide behavior? A 14-year prospective study. Suicide Life Threat Behav. 2002;32:10-32.

81. Swann AC, Dougherty DM, Pazzaglia PJ, Pham M, Steinberg JL, Moeller FG. Increased impulsivity associated with severity of suicide attempt history in patients with bipolar disorder. Am J Psychiatry. 2005;162:1680-7.

82. Baca-Garcia E, Diaz-Sastre C, García Resa E, Blasco H, Braquehais Conesa D, Oquendo MA, et al.Suicide attempts and impulsivity. Eur Arch Psychiatry Clin Neurosci. 2005;255:152-6.

83. Beck AT, Beck R, Kovacs M. Classification of suicidal behaviors: quantifying intent and medical lethality. Am J Psychiatry. 1975;132:285-7.

84. Beck AT, Schuyler D, Herman I. Development of Suicide Intent Scales. In: The Prediction of Suicide. Beck AT, Resnick HLP, Lettieri D, (editors). Bowie, MD: Charles Press Publishers; 1974, pp. 45-56.

85. Hjelmeland H, Nordvik H, Bille-Brahe U, De Leo D, Kerkhof JF, Lönnqvist J, et al. A cross-cultural study of suicide intent in parasuicide patients. Suicide Life Threat Behav. 2000;30:295-303.

86. Freedenthal S. Assessing the wish to die: a 30-year review of the suicide intent scale. Arch Suicide Res. 2008;12:277-98.

87. Williams CL, Davidson JA, Montgomery I.. Impulsive suicidal behavior. J Clin Psychol. 1980;36:90-4.

88. Dorpat TL, Ripley HS. A study of suicide in the Seattle area. Compr Psychiatry. 1960;1:349-59.

89. Li XY, Philips MR, Wang YP, et al. The comparison of impulsive and nonimpulsive attempted suicide. Chinese J Psychiatry 2003;29:27-31. [in Chinese]

90. Brent DA. Correlates of the medical lethality of suicide attempts in children and adolescents. J Am Acad Child Adolesc Psychiatry. 1987;26:87-91.

91. Simon OR, Swann AC, Powell KE, Potter LB, Kresnow MJ, O'Carroll PW. Characteristics of impulsive suicide attempts and attempters. Suicide Life Threat Behav. 2001;32(1 Suppl):49-59.

92. Hawton K. Suicidal Behavior in Children and Adolescents. Newbury Park, CA: Sage; 1986.

93. Brent DA, Johnson B, Bartle S, Bridge J, Rather C, Matta J, et al. Personality disorder, tendency to impulsive violence and suicidal behavior in adolescents. J Am Acad Child Adolesc Psychiatry. 1993;32:69-75.

94. Brent DA, Bridge J, Johnson BA, Connolly J. Suicidal behavior runs in families. A controlled family study of adolescent suicide victims. Arch Gen Psychiatry. 1996;53:1145-52. 
95. Carballo JJ, Oquendo MA, Giner L, Zalsman G, Roche AM, Sher L. Impulsiveaggressive traits and suicidal adolescents and young adults with alcoholism. Int J Adolesc Med Health. 2006;18:15-9.

96. Renaud J, Berlim MT, McGirr A, Tousignant M, Turecki G. Current psychiatric morbidity, aggression/impulsivity, and personality dimensions in child and adolescent suicide: a case-control study. J Affect Disord. 2008;105:221-8.

97. McGirr A, Renaud J, Bureau A, Seguin M, Lesage A, Turecki G. Impulsiveaggressive behaviors and completed suicide across the life cycle: a predisposition for younger age of suicide. Psychol Med. 2008;38:407-17.

98. Coccaro EF, Bergeman CS, Kavoussi RJ, Seroczynski AD. Heritability of aggression and irritability: A twin study of the Buss-Durkee Aggression Scales in adult male subjects. Biol Psychiatry. 1997;41:273-84.

99. Seroczynski AD, Bergeman CS, Coccaro EF. Etiology of the impulsivity/ aggression relationship: Genes or environment? Psychiatry Res. 1999; 86:41-57.

100. Fulwiler C, Grossman H, Forbes C, Ruthazer R. Early-onset substance abuse and community violence by out-patients wuth chronic mental illness. Psychiatr Serv. 1997;48:1181-5.

101. Malone KM, Oquendo MA, Haas GL, Ellis SP, Li S, Mann JJ. Protective factors against suicidal acts in major depression: reasons for living. Am J Psychiatry. 2000;157:1084-8.

102. McGirr A, Alda M, Séguin M, Cabot S, Lesage A, Turecki G. Familial aggregation of suicide explained by cluster B traits: a three-group family study of suicide controlling for major depressive disorder. Am J Psychiatry. 2009;166:1124-34.

103. Conner KR, Swogger MT, Houston RJ. A test of reactive aggressionsuicidalbehavior hypotheses: is there a case for proactive aggression? J Abnorm Psychol. 2009; 118:235-40.

104. Michaelis BH, Goldberg JF, Davis GP, Singer TM, Garno JL, Wenze SJ. Dimensions of impulsivity and aggression associated with suicide attempts among bipolar patients: a preliminary study. Suicide Life Threat Behav. 2004;34:172-6.

105. Shneidman ES. Suicide as Psychache: A Clinical Approach to Self-Destructive Behavior. Northvale, NJ: Jason Aronson; 1993.

106. Orbach I, Mikulincer M, Sirota P, Gilboa-Schechtman E. Mental pain: a multidimensional operationalization and definition. Suicide Life Threat Behav. 2003;33:219-30.

107. Brown MZ, Comtois KA, Linehan MM. Reasons for suicide attempts and nonsuicidal self-injury in women with borderline personality disorder. J Abnorm Psychol. 2002;111:198-202.

108. Joiner TE, Van Orden KA, Witte TK, Selby EA, Ribiero J, Lewis R, et al. Acquired capability for suicidal behavior and its interaction with burdensomeness and belongingness to predict suicide attempts. J Abn Psych 2009;118:6. 
109. Frattaroli J. Experimental disclosure and its moderators: a meta-analysis. Psychol.Bull. 2006;132:823.

110. Frisina PG, Borod JC, Lepore SJ. A meta-analysis of the effects of written emotional disclosure on the health outcomes of clinical populations. J Nerv Ment Dis. 2004;192:629-34.

111. Dervic K, Brent DA, Oquendo MA. Completed suicide in childhood. Psychiatr Clin North Am. 2008;31:271-91.

112. Dejong TM, Overholser JC, Stockmeier CA. Apples to oranges? A direct comparison between suicide attempters and suicide completers. J Affect Disord. 2010;124:90-7.

113. Joiner TE. Why People Die by Suicide. Cambridge, MA: Harvard University Press; 2005.

114. Witte TK, Merrill KA, Stellrecht NE, Bernert RA, Hollar DL, Schatschneider C, Joiner TE Jr. Impulsive youth suicide attempters are not necessarily all that impulsive. J Affect Disord. 2008;107:107-16.

115. Speckens AE, Hawton K. Social problem solving in adolescents with suicidal behavior: a systematic review. Suicide Life Threat Behav 2005;35:365-87.

116. Stanley B, Brown G, Brent DA, Wells K, Poling K, Curry J, et al. Cognitivebehavioral therapy for suicide prevention (CBT-SP): treatment model, feasibility, and acceptability. J Am Acad Child Adolesc Psychiatry. 2009;48:1005-13.

117. Vitiello B, Brent DA, Greenhill LL, Emslie G, Wells K, Walkup JT, et al. Depressive symptoms and clinical status during the Treatment of Adolescent Suicide Attempters (TASA) Study. J Am Acad Child Adolesc Psychiatry. 2009;48:997-1004.

118. Jessor RF. In: Adolescents and Risk: Behaviors, Functions, and Protective Factors (English translation). Bonino S, Cattelino E, Ciairano S, (editors). New York, NY: Springer; 2005, pp. 5-51.

119. Williams JMG. Cry of Pain: Understanding Suicide and Self-Harm. London: Penguin Books;1997. 